\title{
Lección Magistral de apertura del Curso 87/88
}

\author{
Pronunciada por el \\ Exmo. Sr. D. José Luis Pinillos
}

\section{EL FUTURO DE LA MODERNIDAD}

Al leer el título de esta lección, puede que más de uno de ustedes se haya preguntado que a qué viene hablar ahora del futuro de algo tan abstracto y difuso como la Modernidad, existiendo como existe una actualidad nacional tan repleta de problemas concretos y acuciantes. Y sin duda habría en esta objeción mucho de cierto. Expceto que, si se mira bien, tampoco son escasas ni superficiales las razones por las que los españoles debemos ocuparnos - y más siendo universitarios- de los serios problemas que ensombrecen el futuro de la cultura moderna, del cual en muy buena medida depende el nuestro.

España es uno de los muchos países que ha llegado tarde a la Modernidad, pero no es uno de tantos. A diferencia de otros pueblos, el nuestro lo ha hecho de una manera singular, es decir, se ha incorporado al mundo moderno no sólo con retraso, sino a través de serias contradicciones, en medio de tremendos vaivenes y forcejeos internos, combatiendo tenazmente lo que a última hora ha tenido que aceptar más o menos a regañadientes $y$, desde luego, a destiempo, esto es, en el preciso momento en que la Modernidad está en crisis y no acaba de saber muy bien hacia donde dirigir sus pasos.

Esta singular trayectoria histórica ha marcado profundamente, creo yo, nuestra mentalidad colectiva, y continúa influyendo actualmente en nuesra manera de ver la vida y de abordar el futuro. A pesar de lo cual, este es el problema, se trata de un asunto al que apenas se la presta atención. De ahí mi interés por aprovechar esta oportunidad para reflexionar con ustedes sobre el problema. $Y$ a tal fin, comenzaré por hacer algunas puntualizaciones sobre la idea misma de Modernidad.

\section{A qué llamamos Modernidad}

Por supuesto, la palabra Modernidad puede querer decir muchas cosas distintas, que no hacen ahora al caso. Lo moderno puede referirse a lo reciente, a lo último, a lo original, a lo que se opone a lo antiguo y lo supera, o quién sabe a qué más. El vocablo Modrnidad tiene de hecho una larga historia, que se remonta por lo menos a la alta Edad Media, pero aquí y ahora me limitaré a utilizarlo en su sentido actual fuerte, o sea, para referirme a un periodo histórico muy concreto que, como nadie ignora, se abre con la Reforma y los grandes Descubrimientos -el del Mundo Antiguo y el del Nuevo 
Mundo, el de la Ciencia Nueva y cl del Estado Moderno-, se continúa luego con el siglo de las luces, la Revolución francesa y la idea de Progreso, hasta desembocar y tal vez cerrarse en esta incierta sociedad posindustrial en que vivimos, y de cuyo provenir nadie parece estar seguro. En definitiva, pues, a este medio milenio de historia occidental, caracterizado por un vector de secularización y tecnificación creciente que ahora glosaremos, es a lo que habitualmente se llama Modernidad, y a él nos referircmos siempre que en esta conferencia hablemos de la cultura o del mundo moderno.

Desde luego, y no lo discuto, el mundo moderno podría haber sido distinto del que es. Pudo haber triunfado, pongamos por caso, la alternativa española, la Contrarreforma, el Estado ecuménido y la evangelización de América. Pudo no haber habido Modernidad, o haber sido distinta de la que es. Pero no ocurrió así. La Modernidad que históricamente se impuso como tal fue la que conocemos, la que acabamos de apuntar sumariamente hace un instante y vamos a comentar de inmediato. sin duda, insisto en ello, las cosas podrían haber ocurrido de otro modo - la historia no es una geometría-, y en culquier caso caben interpretaciones muy diversas de lo que ocurrió.

Hay quienes como Max Weber, o Harold Laski, sin más lejos, han conferido suma importancia a lso factores religiosos, a la ética del protestantismo concretamente, en el desarrolo de la Modernidad, mientras otros, como Karl Marx, o Karl Polanyi, se han apoyado más en la economía para explicar la gran ruptura del XVIII, sin la que ciertamente es difícil entender lo que acontece ahora. Robert Lenoble, en cambio, concede mucha importancia a la ciencia, y en un espléndido libro sobre la evolución de la idea de Naturaleza (Historia de l'idée de Nature) ha analizado con notable precisión hasta qué punto el mecanicismo de la física del Barroco ha sido, en el fondo, el gran responsable de la actual fisonomía del mundo; de un mundo donde, a la postre, la decepción y el desencanto han concluído por obscurecer las luminarias de la Ilustración. Un poco en esa línea, Martin Heidegger ha achacado la técnica la deshumanización creciente de nuestras formas de vida, si bien el factor radical del desfondamiento de la Modernidad habría que buscarlo, según él, en la pérdida de la condición fundante sufrida por el ser, y puesta de manifiesto en la metafísica cumplida.

Personalmente, opino que la hegemonía alcanzada en la explicación científica por la categoría de relación - a expensas, claro, de la idea de principio- es de hecho una de las claves decisivas para comprender el espíritu de la Modernidad, si se me permite decirlo así. Pero en todo caso, es obvio que las seffas de identidad del mundo moderno se prestan a lectura muy diversas que no es posible desarrollar aquí. El gran problema de la aceleración de los cambios tecnológicos, vaya por caso, o la equiparación de los conceptos de inovación y de valor, en la sociedad contemporánea, son dos ejemplos más de esta diversidad de interpretaciones posibles del hecho histórico en que consiste la Modernidad. En todo este asunto hay, que duda cabe, mucho de opinable. Lo cual en modo alguno debe hacernos perder de vista el hecho histórico de que la Modernidad existió y de que España adoptó frente a ella, en su momento, una actitud de rechazo y de condena, que marcó nuestra mentalidad colectiva con caracteres que, en cierto modo, aún perduran. Esta es la cuestión. Nos guste o no, lo cierto es que entonces, en el XVI y XVII, nos opusimos a lo que ahora hemos tenido que recurrir. En esto, España jugó a la contra de Occidente, con el resultado de que ahora estamos teniendo que recorrer a grandes zancadas en pocos decenios el camino que otros hicieron más 
pausadamente durante siglos. Esta es la gran cuestión, vuclvo a repetirlo por enćsima vez, de que debemos hacernos: intentar adaptarnos a un tiempo histórico que no tiene demasiado que ver la eternidad con que durate siglos España soñó.

\section{Excursus sobre la diferencia española}

Son innumerables los datos que se podrían introducir aquí, desde la famosa pragmática de Felipe II, prohibiendo ir a enseñar o aprender al extranjero, hasta lo ocurrido todavía en nuestro siglo con la teoría de la evolución y el psicoanálisis, o tantas cosas más del mismo estilo. Pero no se trata de recrearse en la suerte, acumulando episodios y anécdotas de mayor o menor relieve, sino de enumerar de forma sucinta y objetiva algunos de los hechos salientes que marcan la singularidad de nuestra postura histórica frente al desarrollo de la Modernidad.

En primer lugar, debemos recordar que no tuvimos Reforma, sino Contrarreforma. El libre examen contó, naturalmente, con la enemiga de la Inquisición, y no hay que olvidar a este respecto que el latín siguió siendo el principal lenguaje de la filosofía casi hasta finales del XIX: prácticamente no tuvimos racionalismo ni idealismo cuando debimos tenerlo. Los novatores y erasmistas no lo pasaron muy bien, que digamos, y los ideales de la limpieza de sangre y desvío hacia el trabajo y el lucro, tampoco ayudaron mucho a fomentar el espíritu innovador y pragmático de la Modernidad. Las guerras en Europa y la singular empresa americana desviaron recursos que podían haberse empleado en la técnica, lo cual habría redundado a su vez en beneficio de la organización social del comercio y del interés por un camino que terminó en el agotamiento y la derrota militar del XVII, a consecuencia de lo cual se extendió por el país una onda de misoneismo, que evidentemente tampoco contribuyó a nuestra modernización. Dicho en pocas palabras, el camino del progreso secular tropezó en la España de entonces con serios obstáculos. A pesar de que no todo el país estaba en la misma postura, la modernización no fue precisamente el punto fuerte de la España eterna. Todo esto es bien sabido, desde luego, pero conviene tenerlo presente a la hora de analizar nuestra postura actual hacia la clase de mundo en que, por fin, parece que nos hemos incorporado de una vez por todas.

La realidad es que, por razones que no discuto, en su momento no seguimos la política pragmática y utilitaria de otros estados modernos, por ejemplo, Francia e Inglaterra. A diferencia de ellos, dedicamos inmensos recursos a la evangelización y aculturación de los indígenas, a los que dejamos Universidades y Catedrales en mucho mayor número que los anglosajones, aunque con escaso provecho material para la metrópoli. Nos volcamos, en suma, en aventuras tan sublimes como poco prácticas, seguimos a fondo la política "divinal" de que habla Américo Castro, a la par que pretendimos frenar el protestantismo en Europa, y descuidamos nuestro progreso científico, nuestro desarrollo socioeconómico. En esas altas empresas nos desangramos sin remisión y nos apartamos de la Modernidad.

Como ya hemos dicho, apenas tuvimos Renacimiento científico, o más bien lo tuvimos interrupto. La ciencia del barroco no acabó de desplazar a la ciencia aristotélica, ni el racionalismo ni el empirismo modernos consiguieron substituir a tiempo a la neoescolástica del XVII. Y para colmo de males, la pujante Ilustración de nuestro 
siglo XVIII, que intentó rectificar el anterior rumbo de aislamiento, cayó bajo la guillotina de la represión y del micdo, juntamente con la cabeza de Luis XVI, para terminar de ser barrida por la guerra de la Independencia. Por otra parte, ni que decir tiene que durante el XIX faltó un pensamiento idealista fuerte, no hubo propiamente una Revolución Industrial ni Social, y la bandera del Progreso se politizó, es decir, en lugar de modernizarse, la sociedad española se esterilizó en un maremagnunm de conflictos internos y de guerras civiles, que nos privaron de la estabilidad necesaria para una acción modernizadora continuada. Un dato bien elocuente al respecto lo representan tal vez los cambios de moneda que hubo en el reinado de Isabel II (al parecer hay catalogadas hasta 600 monedas diferentes), que reflejan la falta de continuidad de la sociedad española de la época. Finalmente, el país no pudo soportar tanta tensión acumulada, tanta cuenta pendiente, y estalló la guerra de 1936. Tengo a mano el Testamento político de Sánchez Albornoz y recojo de él un pasaje que me parece iluminador a este respecto:

"Llegamos al siglo XX - nos dice don Claudio- sin haber padecido las tres grandes revoluciones que habían contribuido a hacer la Europa que cruza la barrera cronológica del 1900. Nosotros nos asomamos al siglo XX sin haber padecido ningún proceso equivalente al de las guerras religiosas de los siglos XVI y XVII, sin haber sufrido procesos revolucionarios equivalentes a la revolución inglesa y a la Revolución francesa, y sin haber conocido los primeros eslabones de las revoluciones sociales de allende el Pirineo. Las otras comunidades las habian padecido sucesivamente. Nosotros hubimos de sufrirlas sincrónicamente. $Y$ esa ha sido la tragadia de la cuarta década del siglo."

A la victoria de los nacionales, siguió un efímero y anacrónico intento de neocontrarreforma, fielmente descrito en el libro de Corts Grau Motivos de la España eterna, que refleja con honestidad el espíritu de aquellos tiempos de vuclta a Trento y al Imperio. Pero de eso más vale no hablar. Fueron los tiempos del ipor el Imperio hacia Dios!, que pronto se transmutaron en los de jadiós Imperio! Eviudentemente, por ese camino no se iba a remediar la "dramática inhabilidad de los españoles... para hacer de su patria un país mínimamente satisfecho de su constitución política y social", a que se refería Pedro Laín en España como problema.

Por fortuna no fue ese el camino que se tomó, y a partir de los años 60 España entró en el proceso de modernización que finalmente nos ha llevado a la entrada en la comunidad europea. Sólo que con tanta rapidez, que la sociedad no ha tenido tiempo de adaptarse a las nuevas exigencias. Quizás ha logrado desprenderse de antiguos hábitos, pero no los ha reemplazado aún del todo por los que corresponden a la nueva situación. Este es el problema de la "diferencia" nacional, que a mi parecer no se ha enfocado adecuadamente. En mi oponión, un análisis de ciertas particularidades de nuestro pasado podría ayudarnos a entender lo que ocurre, podría explicar un poco por qué a veces los españoles de este siglo parecemos vivir en otro, por qué en muchas ocasiones damos la impresión de movernos en el mundo de hoy con los esquemas mentales de otro tiempo. En definitiva, podría servirnos para comprender algo mejor el alcance del desajuste de mentalidades a que me estoy refiriendo, que es precisamente lo que impide a los españoles entender que lo que les pasa es que no entienden lo que les pasa. Lo cual es, a la postre, lo que perpetúa lso anacronismos y retrasa el proceso de readap- 
tación.

\section{En la encrucijada}

Recapitulemos lo dicho. Por razones históricas profundas, España se ha encontrado de pronto en la encrucijada de los tiempos, algo confusa ante la rapidez, profundidad y cuantía de los cambios a que ha de hacer frente. Es sabido que este tipo de situaciones provoca desconcierto: un desconcicrto vital que es comprensible, pero que no es bueno. Esto es lo que ha sucedido. Tener que recorrer en pocos años el camino que otros han recorrido a través de una larga continuidad histórica - palabra clave esta de la continuidad que sigue representando hoy un problema irresuelto- nos ha planteado y plantea problemas de adaptación, que desembocan en un peligroso círculo vicioso o, más bien, en una espiral de rupturas. Como vamos con retraso, los cambios son contínuos; con lo cual nunca se alcanza la continuidad precisa para que los problemas se resuclvan y las cosas lleguen a consolidarse a funcionar normalmente, etc., etc. De hecho, la trasición política, el consumismo, los cambios generacionales, la televisión, y ahora mismo la entrada en la comunidad económica europea, ha alterado hasta tal punto las formas tradicionales de vida y provocado tal confusión, como por lo demás era de prever, que esa temible espiritual de la discontinuidad a que aludía más arriba, corre el peligro de interferir seriamente con el proceso de nuestra modernización. En definitiva, en un abrir y cerrar de ojos, ha caído tabúes seculares, se ha desmitificado lo divino y lo humano, los niveles de decencia pública han descendido de forma notoria, la anomía ha hecho presa en importantes sectores de la sociedad, y el pasotismo ha prendido en la juventud como un reguero de pólvora, para no hablar de las drogas, de la crisis de la familia o de la inseguridad ciudadana. Y para colmo, por si todo eso fuera poco, hace unos años ha entrado además en liza la posmodernidad, una filosofía lúdica $y$ decadente, que en otras sociedades tiene probablemente un sentido y unas consecuencias harto distintas de la que pueda tener aquí. Tengo para mí que hay muchas cuestiones parecidas a estas, que debería tratar de poner en claro la sociedad española, a la vista del complicado futuro que probablemente le aguarda en su proceso de adaptación a Europa. De un lado, es obvio que, a estas alturas, una sociedad medianamente avanzada no puede seguir tomando al pie de la letra los tópicos decimonónicos sobre el Progreso; muy por el contrario, un país que pretenda ponerse al dia, modernizarse con un criterio verdaderamente actual, no puede desoir las insistentes críticas de que la Modernidad está siendo objeto desde hace decenios, por parte de sectores tan diversos como el psicoanálisis, el estructuralismo, el marxismo o la posmodernidad. Expcepto que, de otra parte, no es menos cierto que la crítica a la Modernidad tiene un sentido muy diferente en los países que ya la han conseguido, que en los que todavía no hemos llegado del todo a ella.

Debido a un cúmulo de factores muy diversos, principalmente a la falta de preparación y de experiencia para entender y hacer frente a tanto cambio, los españoles estamos en estos momentos algo confusos y desbordados por la situación, y no muy dispuestos a interiorizar la moral de riguroso cumplimiento que exige la indole del mundo tecnológico a que nos hemos incorprado. A diferencia de la naturaleza, éste es un mundo creado por el hombre y que el hombre mismo ha de mantener con un contínuo 
esfuerzo de dedicación y vigilancia. Es un mundo en cl que no tiene cabida el confiado ¡Dios proveerá! de la tradición, un mundo que necesita de un mantenimiento artificial, de una continuidad de esfuerzo colectivo, de un trabajo en equipo, de una disciplina y de una moral de exigencia, que no acaban de compaginarse bien con las formas de vida individualistas e indisciplinadas propias de otros tiempos.

Por otra parte, también tengo la impresión de que los españoles de hoy no queremos enterarnos de nada que pueda enturbiar nuestra actual situación, ni por supuesto nos sentimos entusiasmados con la forma de vivir de otros paises donde el trabajo, el orde y la racionalidad económica ocupan un lugar mucho más destacado que aquí. Posiblemente, España esté cansada de tanta tragedia, de tanto cambio y tanto esfucrzo como se ha sucedido en los últimos lustros, y se resiste a salir de nuevo a la arena, esto es, no quicra aceptar una situación que vislumbra como problemática y necesitada de un nucvo esfuerzo colectivo. Es muy comprensible. A las nuevas generaciones tampoco se las ha educado para el heroismo y el sacrificio. Eso suele ocurir después de las guerras y en periodos de bienestar. También se entiende. Pero a la larga, con independencia de que lo entendamos o no, esconder la cabeza debajo del ala no resuclve los problemas cuando se presentan. $Y$ la verdad es que los hay... Qucrámoslo o no, nos agrade o nos disguste, la verdad es que más tarde o más temprano los españoles habremos de optar por alguna alternativa de futuro, habremos de decidir por donde tirar en esta encrucijada de la Modernidad, aunque la decisión consista en dejarnos llevar adonde decidan otros, o en ir dando tumbos al albur de las circunstancias.

Dicho de otra forma, esa decisión depende en gran medida de nosotros, forma parte de la respuesta responsable consustancial al comportamiento del hombre. La historia humana no es a la postre una historia euclídea, deductiva; no es una historia donde los hechos se deduzcan como un sistema de teoremas y corolarios, a partir de unos axiomas indiscutibles. Hay una enorme dosis de contingencia y opcionalidad subjetiva en la vida de los pueblos: tanta, por lo menos, como en la biografía de los idividuos. Y ello acontece no sólo por virtud de que las circunstancias varian, sino asimismo por obra y gracia de las fantasías colectivas y los proyectos vitales que genera cada comunidad, por virtud del modo y manera en que las gentes anticipamos y propiciamos nuestro futuro: lo por venir, que en cierto modo es también lo por traer. Los seres humanos, reparemos en ello, no respondemos tanto a lo que las cosas son como a lo que creemos que son y queremos que sean, esto es, respondemos al mundo como voluntad y representación, si se me permite simplificar el pensamiento de Schopenhauer. Analizadas las cosas desde esta óptica subjetiva, el tema de nuestro actual desconcierto frente al reto de la Modernidad cobra inmediatamente un gigantesco relieve, donde el problema de las mentalidades ocupa un lugar central. Huelga decir que si este tipo de reflexión sobre la anticipación del futuro es siempre importante, lo es todavía mucho más en momentos como los actuales, en que es menester tomar decisiones graves en el seno de la confusión.

Si en la encrucijada de la Modernidad, la reflexión sobre el futuro lleva para los españoles un sello de urgencia.

\section{Los tópicos del progreso}

Al mantenimiento de ese estado de confusión contribuye por supuesto una serie de 
tópicos que aún circulan sobre la naturaleza del progreso, de la ciencia y de la tecnología: sobre todo, cuando de lo que se habla es de las "nuevas tecnologías", en plural. Porque si es malo ignorar lo que son las cosas, más grave aún es saber lo que no son, creer que se sabe. Que es lo que acontece con los tópicos sobre el Progreso y la Modernidad. Desde esa presuntuosa ignorancia, y perdónenme el exabrupto, no hay cristiano que pueda hacer nada a derechas, ni a izquierdas.

Es claro que una sociedad medianamente ilustrada hoy no puede enfrentarse al proyecto de la Modernidad con la misma ingenuidad con que lo hicieron nuestros abuelos. Scría absurdo que actualmente, después de Hiroshima y de dos horribles guerras mundiales, siguićramos creyendo a pies juntillas una serie de ideas que pasaban poco menos que por dogmas de fe ante los ojos de nuestros abuelos. Es obvio que para hacer frente a la situación actual es preciso contar con una cierta conciencia crítica de la socicdad, a la que para ello hay que dar elementos de juicio al respecto. Por ejemplo, en la actualidad no es serio continuar creyendo que el progreso es una propiedad natural de la vida humana, como se creía hace un siglo. Tampoco es de recibo aceptar sin más que la propiedad de progresar, en la medida en que exista, ha de ser meliorativa sin más, o sea, apta para mejorar automáticamente la totalidad de la existencia humana, como por ejemplo creyeron los ilustrados del XVIII y muchos socialistas utópicos. También seria muy difícil de justificar hoy la típica creencia de que todo lo nuevo es valioso y todo lo antiguo deleznable, siendo así que evidentemente hay innovaciones detestables - iserá preciso poner ejemplos?-, y cosas antiguas inmejorables, o que mejoran con el paso de los años, en lugar de hacerse obsoletas y a las que en definitiva no es posible aplicar la medida cuantitativa del progreso material. Quedan asimismo ya muy atrás los tiempos en que se aceptaba que el progreso humano es ilimitado, controlable y siempre beneficioso. En los umbrales del siglo XXI no puede continuarse repitiendo que la ciencia y la técnica conducen necesariamente a la felicidad. Una y otra, la ciencia y la técnica, son en principio neutrales, ambas son susceptibles de ser puestas al servicio de la plenitud del hombre, o de su explotación y servidumbre, aparte de que el brazo destructivo de la tecnología sea más largo y más poderoso que el de la reconstrucción. La Modernidad ha resultado equivoca a ese respecto. La sabiduría de la vida no le es propia, y eso lo ha intuído la posmodernidad. Frente a cuyas críticas de la Modernidad, sin embargo, hay que tomar precauciones.

\section{La crítica posmoderna}

De la posmodernidad, en efecto, hay mucho que tomar y dejar. Hay en ella un elemento crítico muy aprovechable y otro que no me lo parece tanto, y que tal vez fuese imprudente tomar en España como fuente de inspiración. En todo caso, pienso que una reflexión sobre el futuro de la Modernidad difícilmente puede hacerse al margen de la crítica posmoderna, aunque tampoco sea sencillo hacerlo exclusivamente desde ella. El discurso posmoderno es ambiguo y multiforme, tiene, versiones muy distintas, si bien podría aceptarse que todas tienen como elemento común un sentimiento de decepción frente a las posibilidades de la Modernidad para hacer frente a los problemas que ella misma ha provocado. Así, pues, aunque no sea nada fácil componer un repertorio de los rasgos distintivos de la mentalidad posmoderna, por lo que hace a la crítica de la 
Modernidad sí cabe señalar algunas de sus características más notables.

De alguna manera, el pensamiento posmoderno reposa sobre una "filosofía" propensa a entronizar la frivolidad; es un pensamiento claramente inclinado al rechazo de los grandes relatos y de los mensajes históricos, una cultura volcada al desmotaje y desmitificación de todo lo ejemplar, aficionada a poner en solfa los clásicos y a irritar al burgués, propicia a ensalzar la zafiedad, la incongruencia, el desorden y todo lo que contribuya a desestabilizar lo establecido. En esa mismo línea, y frente a la igualdad en la universalidad de la razón proclamada por lo ilustrados, los posmodernos tienden al cultivo de una filosofia antisubjetiva - contraria a la tesis del sujeto universal-, de un filosofia de la "diferencia", cosa que probablemente encaje a las mil maravillas con la mentalidad de un país donde eso de ser diferente se da bastante bien. Por otro lado, cuando los posmodernos anuncian el fin de la modernidad no hay que pensar en el fin de los tiempos, ni en un holocausto nuclear, ni en catástrofe alguna - lo cual es de agradecer-, sino más bien en una manera menos agresiva y arrogante, en un modo más débil de entender lo nuevo. Tesis que se acompasa, insisto, con la existencia de una decepción y de una hostilidad - ¿tal vez temor? - frente a una modernidad que se tuvo por eterna, que llegó a creerse indefinido repuesto de sí misma, y que finalmente ha logrado situarnos a las mismas puertas del cataclismo universal.

Puesto ya en el trance de tener que abreviar mi exposición, añadiría quizá alguna nota más de las que, a mi parecer, podrían servir para completar el perfil o retrato robot de la crítica posmoderna. A lo ya dicho agregaría acaso el escepticismo frente a la racionalidad científica, un cierto sentimiento de impotencia ante las cosas, por virtud del cual el posmoderno tiende a reducir las condiciones de su discurso a un mero discurso sobre las condiciones, esto es, a pura ingeniosidad verbal que se queda en nada, que conduce a un nihilismo "light", donde el valor incondicionado de lo nuevo ya no es un dogma, y donde tampoco se buscan soluciones a las cosas. En realidad y de verdad, lo único que en el fondo le gusta al posmoderno es el juego frívolo con los conceptos, la desestabilización de lo que se creía perenne, la disolución de los principios y los fines, y de la propia subjetividad que soñaba con integrarlos en un movimiento de realización personal: en suma, la instalación lúdica en lo efímero. En esto consiste básicamente el regusto posmoderno: jamás en la búsqueda de soluciones, porque ello sería tanto como caer de nuevo en la lógica del desarrollo, que es la gran trampa de que el posmoderno dice querer protegerse a toda costa.

No sé, no estoy seguro, pero veces sospecho que la verdad que se esconde tras esa máscara de frivolidad decadente no es sino un profundo sentimiento de impotencia ante lo que se teme que avecina. O sea, el deseo de pesar menos para flotar más entre los restos del naufragio. Como quiera que sea, dudo mucho de que Espana esté todavía para veleidades tan refinadas.

\section{Ante el futuro}

$Y$ ahora viene la pregunta. ¿Realmente, es que la filosofia posmoderna puede constituir un buen apoyo como elemento de orientación ante el futuro? ¿Es que acaso la prosecución del desarrollo debe de considerarse una trampa en un país como España, donde todavía hay tantos problemas materiales sin resolver? ¿No será un pretexto para 
reincidir en lo de siempre, para apostar de nuevo contra la Modernidad? O mejor aún, ¿no sería en el fondo una diversión de señoritos, impropia de un país donde todavia hay tanta necesidad por remediar?

Sinceramente, yo pienso que antes de llegar al juego de las frivolidades, a los españoles nos queda todavía mucho camino por hacer.

Estar de vuelta de las cosas antes de haber llegado a ellas es un viejo vicio español, del que debemos cuidarnos. Otros demonios familiares ya se han desvanecido. El cainismo y la ferocidad de otros tiempos han dado paso a formas de convivencia más acordes con la vida moderna. Salvo excepciones, los extremismos van siendo reemplazados por una mayor tolerancia política y religiosa, producto tal vez más del escepticismo y la indiferencia que de otra cosa, pero palpable. Lo que no veo que vaya tan bien, y aquí vuelvo a cosas que ya he dicho, es la voluntad de trabajar en equipos, de trabajar unos con otros en vez de unos contra otros; lo que echo de menos es el entusiasmo al servicio de un proyecto de vida en común. Frente a las exigencias de rigor que inevitablemente reclama la participación sería en un mundo tecnológico, son todavía demasiados los españoles de hoy que se encogen de hombros, que no quieren saber nada de lo que pueda complicarles la vida. $Y$ esto no es bueno. Si las nuevas gencraciones cedieran a la tentación del abandonismo, o se entregaran a una frivolidad prematura, mal les iba a ir en el competitivo mundo que se les viene encima. Yo creo firmemente que, entre las misiones actuales de la Universidad, una de las más importantes es la de difundir la idea de que ara defenderse en el mundo actual no basta con disponer de una tecnología prestada. La tecnología se importa. No así, sin embargo, la moral que la mantiene, que la perfecciona y que confiere a un país los grados de libertad indispensables para tener voz y voto en el concierto de los pueblos civilizados. Esa moral no se importa y no es sólo individual. Es una moral de esfuerzo y cumplimiento, sin la que no hay futuro en la Modernidad, o en lo que eventualmente pudiera reemplazarla.

Voy a terminar. La historia de los pueblos se compone, igual que la de los individuos, de lo que hacen y de lo que les ocurre. A los países les ocurre la geografía, los vecinos $y$, en buena o mala medida, lo que han hecho sus antepasados: las guerras, las ciudades y, desde luego, las ideas recibidas, los sentimientos transmitidos, la historia aprendida en la escuela, la herencia del pasado, en suma, y los condicionamientos que les sobrevienen. pero el ser humano no se reduce a sus condiciones, es algo más que el resultado de unos condicionamientos previos: además de efecto de unas causas, el hombre es también, y muy principalmente, proyecto, causa de efectos que se originan en su propia interioridad. El hombre es coautor, digámoslo así, de su porvenir, es un ser que se distigue por darse destino, que es, como dice Marias, futurizo. A diferencia de lo que ocurre con la respuesta animal, la respuesta humana es responsable, tiene mucho de iniciativa y de propuesta, no es una mera reacción a los estímulos que proceden del mundo exterior, sino que está mediada por un mundo interior en el que intervienen la fantasía y los deseos. Es en ese mundo íntimo donde se gestan los proyectos de futuro, y donde a última hora los españoles habremos de decidir lo que hay que hacer con esa Modernidad que, después de todo, tan sólo los tontos deprecian antes de haberla conseguido.

Tal es, en fin, el sentido de mi propuesta: rogar a los españoles que no descuiden 
este asunto, que reflexionen algo más a menudo sobre el futuro de la Modernidad, que es el nuestro y que al fin y al cabo tampoco es tan detestable. Sabemos que cuando un pais se incorpora a destiempo a la civilización industrial, corre el riesto de perder la moral que tenía, sin alcanzar la nueva, la que necesita para moverse con acierto por el complejo mundo de tecnologías e intereses sobre el que la Modernidad reposa. Sabemos también que de este peligro no está ciertamente exento nuestro país. Por ello, no sería bueno que la Universidad se cruzara de brazos ante un asunto en que tanto nos va. Después de todo, rectificar los errores algo tiene que ver con la sabiduría.

Melilla, octubre de 1987 